\title{
Unhealthy Eating Practices: Identification of Contributing Factors amongst the Youth in Shimla
}

Karan Berry*

Abstract

Eating habits have been a major concern amongst the youth as a determinant of health status.

There has been a major change in the eating habits of the young, with an increase in consumption of animal products, starchy food (fries and potato chips) and fats. Eating out is on the rise and is likely to be associated with a much higher intake of calories and fats. Working conditions often demand long, irregular hours in front of computers, with fast food and aerated soft drinks within easy reach. Peer pressure is significantly responsible for a dramatic rise in alcohol and smoking (India Today, 2013).

This qualitative study aims to assess the pattern of eating habits and its contributing factors along with defining the areas where prevention, intervention and education can play a vital role in guiding the youth towards healthy eating habits. Several unhealthy eating habits researched through available secondary resources and collection of contributing factors through interviews and questionnaire response of the youth form the methodology for this study.

Bahra University, Dist. Solan, Himachal Pradesh, India; karanberry@ymail.com 
The contributing factors that are identified like poor nutritional education, family environment, peer influence, work pressure and monetary status are finally grouped under four major categories namely Individual, Economic, Social and Environmental factors.

The suggestions provided for abstaining the youth from unhealthy eating may be useful for creating awareness, hence developing a healthy mind and body in today's youth.

Keywords: Unhealthy, Eating Habits, Modern lifestyle, Youth.

\section{Introduction}

The term eating habits (or food habits) refers to why and how people eat, the foods that they eat, and with whom they eat it, as well as the ways people obtain, store, use, and discard food. Individual, social, cultural, religious, economic, environmental, and political factors all influence people's eating habits (Judith C. Rodriguez, 2016). Socialization which involves families, schools, community, government and international health organizations play an active role in developing healthy eating habits amongst the youth.

Countries around the world are confronted with obesity related social and economic costs as it is associated with considerable problems. There has been a recent increase in research studying how to communicate healthy eating habits and the role of various socializing agents such as parents, government agencies, teachers, and peer groups.

Unhealthy food choices increase the risk of lifestyle diseases like cancer, heart attack, diabetes and various other health problems. Over-consumption of certain foods, dietary deficiencies and excessive intake of saturated fats and refined or processed foods affect people at both ends of the socio-economic spectrum, with different types of diseases.

Poor dietary choices and eating habits can cause weight gain during college. It has been found that students no longer meet the required servings of fruit and vegetables on the food pyramid (DeBate, Topping \& Sargent, 2001).The main source of food for 
students living on college campuses is dining halls. Most university dining halls provide a buffet style food system that provides a wide variety of food and allows students to eat anything they want without any restrictions on amount (Peterson et al., 2010). Food advertising, especially for unhealthy foods may be one of the reasons that affect the food preferences. Youth should take upon the responsibility of learning more about diet and nutrition along with making healthier food choices. Fatty and fried foods are good in moderation, but they tend to be abused, which causes a significant difference in body image and weight of an individual.

As with many behaviors, healthy eating habits are more likely to take a foothold in adults if they are established at an early age. Yet, at the turn of the 21st century there were over 155 million overweight children and youth in the world (Lobstein, Baur \& Uauy, 2004).

The wide variety of food available ranges from healthy food such as fruits and vegetables, to high fatty and starchy foods, such as desserts, pizza and French fries. In one study, students stated they went into dining halls knowing what to eat, but as soon as they saw the food available, many times their minds changed (Nelson et al., 2009).

Most often, places with affordable food for students are fast-food restaurants which provide high fatty foods at a cheap price. One study found that between male and female college students, females were more likely to consume high fatty or fried foods (Racette et al., 2005).

\section{Challenges}

Adolescents' perceptions of eating communication need study, since teenagers are gradually becoming more independent in both their thinking and behavior (Eysenck, 1998). In addition to parents, teachers, peers and governments, food advertisements often target children, and may encourage them to pressure their parents to purchase foods with poor nutritional value (Kelly, Turner and McKenna, 2006). In 2004, an estimated US\$15 billion was spent in the United States on advertising and marketing directed at children and youth, of which a major share was food and beverage 
marketing (Schor, 2004).Their perceptions of healthy eating, and the social influences on these perceptions, are unclear. Social service marketers try to promote good eating habits directly to children and indirectly through their parents (Mueller, 2007). Effectively communicating healthy eating messages to young people requires a solid understanding of their perceptions of healthy and unhealthy eating habits, their perceptions ofvarious socializing agents, the other sources communicating with them about eating, and their perceptions of different communication appeals (Chan, et al., 2008 in press).

Stress may arise from making necessary changes to lifestyle while managing the challenges of course loads (Wichianson et al., 2009). Majority of the youth population is living under emotional and physical stress due to rising competition for getting admission to a reputed college and thereafter getting a respectable job.

Schools and Colleges provide athletic equipment and aerobic classes for students, but if they do not provide instructional classes for students on how to use those machines, it can be difficult for beginners to learn and practice. Social influence is also referenced as encouraging the consumption of unhealthy foods. Healthy eating habits are developed through socialization, in which families, schools, community, government and international health organizations may all play an active role.

Previous research has found that many adolescents do not perceive a need or urgency to adopt healthy eating because the long term benefits of good health seem too far away. As a result, the perceived benefits fail to outweigh the short-term advantages of convenience and immediate gratification (Neumark-Sztaineretal., 1999).

Schools and colleges have become more stressful with a heavy amount of work and lots of deadlines. In times of stress, students tend to overeat and choose unhealthy foods. Exercising tends to be at the bottom of the list, and leisure time tends to be minimal. Students usually engage in drinking to help them forget about school. Due to the high amount of calories in alcohol, drinking excessive amounts can lead to obesity. 


\section{Objectives}

Keeping in view all the above facts, a study is thus designed with the following objectives:

1. To identify the unhealthy eating habits amongst the youth through available secondary data.

2. To investigate the factors contributing to unhealthy eating practices amongst the youth in Shimla.

\section{Research Methodology}

The research design used for this project is exploratory in nature. The study approach is predominantly based on qualitative methods. Data is collected from primary sources like self administered questionnaire and interview with school and college going students in the age group of 16-21 years. Secondary resources like various journals, magazine, newspapers, brochures and websites are referred to highlight the effects of unhealthy eating practices.

A total of 200 youth in Shimla were selected to be a part of this study based on purposive sampling technique.

Objectives and benefits of the study were explained to respondents orally and in a written form attached to the questionnaire. They were assured that the information obtained from them would be kept confidential.

\section{Study Instruments}

The questionnaire consisted of three parts:-

The first part included questions on demographic data such as age, gender, education level, family background, lifestyle and living circumstances.

The second part included questions on eating habits and type of meals consumed, such as frequency of meals, type of meal, vegetables and fruits consumption, daily water intake, consumption of junk food, etc. 
The third part included questions on psychological factors that influence dietary habits of respondents like: "eat because of feeling lonely", "feel out of control when eating", "eat so much until stomach hurts", "eat because of feeling upset or nervous", "eat because of feeling bored" and "eat because of feeling happy". The response options were 'Yes' or 'No'.

\section{Data analysis and Interpretation}

Data collected through response generated by 200 questionnaires is subjected to tabulation and analysed through deductive approach to interpret the findings of the study.

\section{GENDER PROFILE}

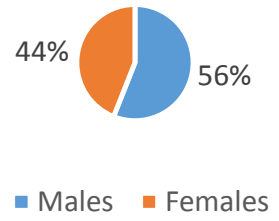

Figure 1 Gender Profile

A total of 15 pre-identified unhealthy eating practices are listed down along-with the probable contributing factors in the questionnaire designed for the youth.

Table I List of Unhealthy Eating Practices along with probable contributing factors and ill effects on human body.

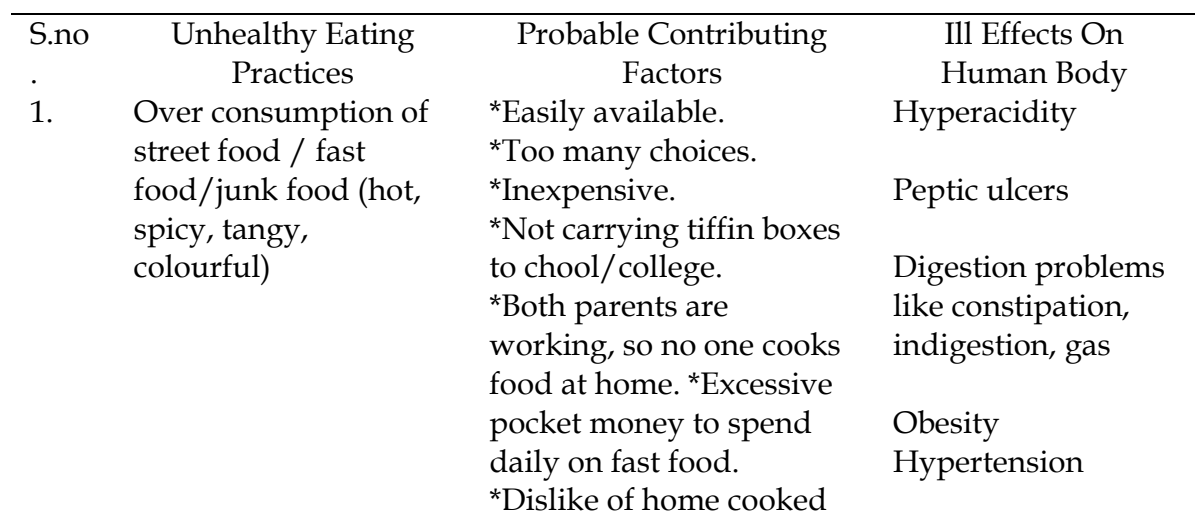




\section{Skipping important meals of the day}

3. Indulgence in various forms of intoxication (smoking, drinking etc.)

4. Food binging (Overfeeding)

5. Irregular meal timings (subduing hunger)

6. Not consuming healthy food products (fruit and vegetables, dairy products etc.). Using low cost ingredients, spices and oil for cooking at home.

Drinking very less water than normal requirement of the body

7. Unhygienic eating habits (Not washing hands before eating, Consuming infected food from street food as it lacks taste and variety.

*Not bringing lunch boxes from home.

Weakness

Obesity

*No time left because of work pressure

(Homework, Assignments, Projects, Exams)

${ }^{*}$ Not feeling hungry due to intoxication.

*No parental control.

*Bad company of friends.

*Feel big factor (Heroic Bad effect on Liver image).

*Excessive pocket money. *Inquisitiveness to try something new.

*Depression due to family problems.

*Physical and emotional stress.

*Inferiority complex in slimmer students, as they are bullied by stronger students.

*Saving time for other social activities.

*No health consciousness. Weakness *Work pressure.

Fatigue

*Busy in other activities.

*Not aware about the

Indigestion

Malnutrition

importance of healthy food products in the diet. *Parental lack of concern over child's health.

Obesity

Fatigue

*Healthy food products

are expensive as compared to junk food.

Food poisoning

Indigestion

Constipation

Accumulation of toxins in the body

*Not aware about the importance of food safety and hygiene in maintaining healthy body.
Food poisoning (vomiting, headache, diahhorea, headache) 
vendors, Eating

without brushing of

teeth)

8. No physical exercise (yoga, gym, dance, aerobics, outdoor sports activities etc.)

9. Overconsumption of convenience food and beverage products (soft drinks, packaged snacks etc.)

10. Distraction while having meals (surfing internet, watching television, talking on mobile phones etc.)

11. Excessive dieting to loose weight (Frequent fasting schedules)

12. Selective eating (having only few chosen food items every time) Imbalanced diet Drinking water before every meal
*Family environment (Unhealthy food eating practices being followed at home).

*Lack of health consciousness.

*No time (Busy on social networking sites).

${ }^{*}$ No health consciousness.

*Easy availability.

*Not so expensive.

* Ready to eat.

*Parents not at home.

*Don't know how to cook

*No other means of

recreation.

*No one available at home to talk-to.

${ }^{*}$ Non availability of physical activity centers near home (like gym, dance institute, sports stadium, park etc.). *Misconception that dieting is good for maintaining attractive body.

*Inferiority complex in fat students.

*Desire to attract and impress opposite sex. *Religious influences-in order to impress God and achieve success.

*Not knowing the concept Indigestion of balanced diet and its importance for maintaining healthy body.

*Misconception regarding certain foods that they may cause obesity even in smaller quantity (eg.

Butter \& Cheese).

*Dislike of green vegetables, fruits, pulses
Tooth decay

Dental cavities

Indigestion

Obesity

Toxins

accumulation in the body

Obesity

Fatigue

Deficiency diseases

Indigestion

Obesity

Extreme weakness

Malnutrition

Deficiency diseases
Weakness

Malnutrition

Nutritional

deficiency diseases 
13. Overcooking of vegetables Cooking of green vegetables without covering
14. Use of excessive salt in food

15. Consuming more sugar than required by the body and dairy products.

*Not aware of the various Vitamins and cooking methods to be used for different food ingredients, so that their taste, texture and nutrition can be maintained. of important minerals deficiency diseases due to loss minerals and vitamins from the vegetables eg. Anaemia, Short sightedness, dry eyes, night blindness, weak teeth and bones, delay in clotting of blood and wound healing. Hypertension (High blood pressure) leads to anger, depression and stubborn attitude.

Diabetes (if insulin production is affected)

Tooth decay

Dental cavity

*Unaware of the ill effects of excess sugar in human body.

Source: Available secondary data

All the responses generated through questionnaires are categorized into four major contributing factors namely Individual, Economic, Social and Environmental factors. 
Artha J Soc Sci

ISSN 0975-329X 


\section{Findings}

The findings of the study reveal that youth's perception of healthy and unhealthy eating has been shaped majorly by Individual $(86 \%)$ and Social $(84 \%)$ factors.

Table III Severity of contributing factors

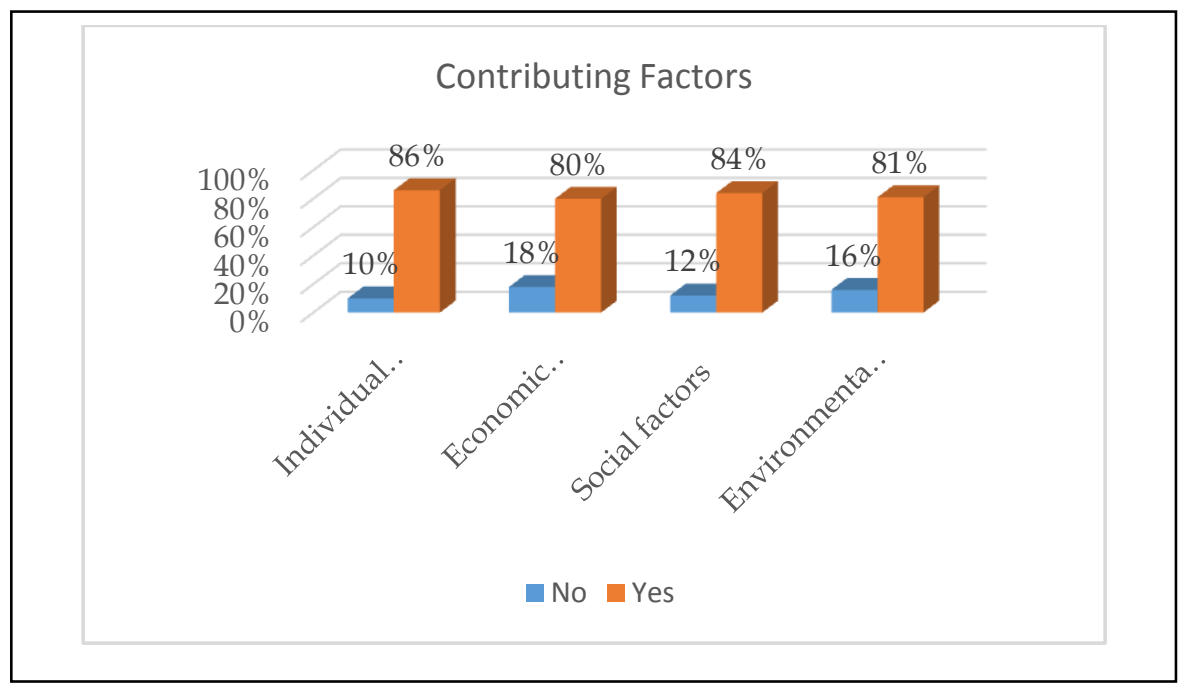

Source: Field survey

Most of the school and college going students are not getting proper nutrition due to their unhealthy eating habits. Across the study it was found that this is especially true for fruit and vegetable intake amongst the youth. Most of the respondents also expressed a lack of interest and initiative to incorporate these food groups in their diet.

Males, who constitute $56 \%$ of the total respondents, demonstrated a bias towards incorporating protein rich foods such as meat and eggs into their diet but ate fewer meals than females. On the other hand females, who constitute $44 \%$ of the total respondents, ate fewer food groups as a part of each meal but seemed to incorporate slightly more fruit into their diet.

Female participants mentioned the importance of calcium intake, as advised sometimes by their mothers, but none of the male participants reported calcium as important. The female participants' awareness of calcium intake in a healthy diet may also 
have been generated from heavy commercial advertising campaigns.

Male adolescents responded as if they were more sensitive to price change than the females. Female adolescents may not consider price an important factor in snack purchase decisions. School and college going students reported under consumption of fruits and vegetables as well as other food groups. Environmental and Economical factors were identified as unpopular reasons for consuming unhealthy foods, whereas Individual and Social factors emerged as major factors for unhealthy eating amongst the youth.

The results show that money does not affect all the students equally but disproportionately affects students of lower economic classes. Students today have busy lives because they are not only students but workers, volunteers, and participants in campus organizations. Prices of food have also lead students to seek out cheaper, often unhealthy food choices. Unfortunately, eating healthy food costs more money in our society.

Lack of time and cooking knowledge were a few important points that reflected across the survey responses and student interviews. Numerous students cited having a busy schedule as a major player in pushing them towards convenience foods, which they viewed as easier and quicker as they require little or no preparation at all. Students expressed their feeling of being discouraged to buy fresh produce because of short shelf life compared to convenience foods. Though the food prepared at home has less sugar, spices, oil, salt, and are MSG free, the respondents were disinterested towards having home cooked food because of less taste and lack of presentation.

Youth most often consume unhealthy foods such as soft drinks, potato chips, and chocolates at parties, social gatherings and during festivals. Respondents revealed that they experience peer pressure to prepare or to consume unhealthy food and snacks in social contexts. Most of the respondents pointed out that unhealthy snacks were handy, while healthy snacks for parties would take a long time to prepare. They also did not know how to prepare healthy foods for social gatherings. Majority of male respondents expressed regret that they did not have enough allowance to dine 
at places that provide more healthy choices. Few male and female respondents admitted that they often drank cola and coffee while preparing for examinations in order to keep them alert.

\section{Suggestions}

There are several areas of opportunity for prevention, intervention and education within the school and college student demographics. Manufacturing and providing healthier convenience foods since students demonstrate a preference for convenience food that requires little or no preparation, providing healthier convenience foods is one option for intervention.

Remind students to eat a variety of food, especially fruits and vegetables

Preparation of diet chart so as to remind students to eat a variety of food, specifically fruits and vegetables, is another area for significant improvement. Many students may have an understanding of healthy eating, but forget to eat a variety of food groups without reminders about the long-term benefits of eating right at the young age.

\section{Training students for food management and healthy cooking}

College students may be guided towards managing fresh foods that might get spoilt easily, so that it becomes less likely for the youth to go for convenience foods. Healthy eating can be made easier for a busy student by providing recipes and meal ideas that can be made in variation with a few basic ingredients.Social influence may encourage and inspire students to make easy and nutritious meals recommended to them by peers.

\section{Sessions on importance of balanced diet}

Schools and colleges should emphasize upon delivering sessions on importance of balanced diet and healthy growth and development amongst their students. 


\section{Conclusion}

Nutritional education amongst the youth should be encouraged to promote healthier eating habits and lifestyles, as well as adherence to the healthier traditional food. Consumers should themselves take responsibility for making healthier food choices by learning more about diet and nutrition essential for being healthy.

Manufacturers should focus upon producing high-end, valueadded products which satisfy the customer needs, for example strategies to increase market penetration and product development of malted health and energy drinks are recommended to enhance growth amongst the health conscious customers. Convenience food manufacturers should give effective and healthy advertisements in electronic, print and internet media for available healthy food choices so as to reach and attract more youth.

To conclude, effective health communication needs to be based on a sound knowledge of young people's perceptions about healthy and unhealthy eating habits, influenced by various socializing agents and other sources.

This paper is a reminder to the students on factors that can affect one's figure and what precautions should be taken when engaging in certain unhealthy habits. While some of these factors are found in all adults' lives, the unique combination of all of these factors in youth means that their health may be at severe risk.

\section{References}

Chan, K., Prendergast, G., Gronhoj, A. and Bech-Larsen, T. (2008, in press), "Communicating healthy eating to adolescents", Journal of Consumer Marketing.

DeBate, Rita D., Marvette, Topping., and Roger G, Sargent. (2001). Racial and Gender Differences in Weight Status and Dietary Practices among College Students. Adolescence. 36 (144), 819.

Department of Health. (2005). Healthy lifestyle to tackle obesity. Retrieved from http:/ / www.info.gov.hk/dh/new/index.htm (accessed May 30, 2016). 
Eysenck, M. (1998), Psychology: An Integrated Approach, Addison Wesley Longman,England, UK.

India Today. (2013, May 31). Death in the Fast Lane: Work pressure, unhealthy eating habits, stressful lifestyle have led to a dramatic rise in heart disease among young Indians. Retrieved from http:// indiatoday.intoday.in/story/rise-in-heart-disease-among-youngindians-work-pressure/1/277761.html (accessed June 10, 2016).

Judith C. Rodriguez. (2016). Eating Habits. Retrieved from http://www.diet.com/g/eating-habits (accessed June 10, 2016).

Kelly, J., Turner, J. J. and McKenna, K. (2006), “What parents think: Children and healthy eating", British Food Journal, Vol. 108 No. 5, pp. 413-432.

Lobstein, T., Baur, L. \&Uauy, R. (2004). Obesity in children and young people: A crisis in public health.Obesity Reviews. 5 (1), 4-85.

Mueller, B. (2007), "Just where does corporate responsibility end and consumer responsibility begin? The case of marketing food to kids around the globe", International Journal of Advertising, Vol. 26 No. 4, pp. 561-564.

Nelson., Melissa,C., Rebecca, Kocos., Leslie, A., Lytle \& Cheryl, L., (2009). Understanding the Perceived Determinants of Weight-related Behaviors in Late Adolescence: A Qualitative Analysis among College Youth. Journal of Nutrition Education and Behavior. 41 (4), 287-292.

Neumark-Sztainer, D., Story, M., Perry, C. and Casey, M.A. (1999), "Factors influencing food choices of adolescents: Findings from focusgroup discussion with adolescents", Journal of the American Dietetic Association, Vol. 99 No. 8, pp. 929-937.

Peterson, Sharon., Diana P. Duncan., Dawn B. Null., Sara L. Roth \& Lynn Gill. (2010). Positive Changes in Perceptions and Selections of Healthful Foods by College Students after a Short-Term Point-ofSelection Intervention at a Dining Hall. Journal of American College Health 58(5), 425-431.

Racette, Susan B., Susan S. Deusinger., Michael J. Strube., Gabrielle R. Highstein\& Robert H. Deusinger. (2005). Weight Changes, Exercise, and Dietary Patterns during Freshman and Sophomore Years of College. Journal of American College Health. 53 (6), 245-251.

Schor, J.B. (2004), Born to Buy: The Commercialized Child and the New Consumer Culture, Scribner, New York. 
Wichianson, Jatturong R., Stephanie A. Bughi, Jennifer B. Unger, Donna Spruijt-Metz and Selena Nguyen-Rodriguez. (2009), "Perceived stress, coping and night-eating in college students." Stress $\mathcal{E}$ Health: Journal of the International Society for the Investigation of Stress 25(3):235-240. Retrieved from http://search.ebscohost.com/ login.aspx? direct= true\&db=aph\&AN=43595815\&site=ehost-live.(Accessed July 10, 2016) 